\title{
LETRAS LENCHAS: HACIA UN RECORRIDO HISTÓRICO DE LA LITERATURA LÉSBICA EN MÉXICO 1
}

\author{
Alicia V. Ramírez Olivares ${ }^{2}$ y Jorge Luis Gallegos Vargas ${ }^{3}$
}

\begin{abstract}
Letras lenchas: hacia un recorrido histórico de la literatura lésbica en México
Resumen: El discurso homoerótico en México se ha forjado en el último siglo a través de manifestaciones artísticas y medios de comunicación; en esta formulación, la literatura, a partir de los años ochenta, ha jugado un papel determinante para darle voz a aquellos que, gracias al discurso oficial, han sido silenciados. La lesboliteratura encontró en el siglo XIX, principios y mediados del XX, un espacio silenciado por prejuicios sociales, doble moral y rechazo inminente de la población que consideraba al no heterosexual como enfermo, rarito o desviado. Fue hasta los años ochenta, con la aparición de Amora (1989) de Rosamaría Roffiel, que las letras sáficas encontraron un espacio para ser contadas. El siguiente trabajo presenta sólo algunos de los libros más importantes que se han escrito de narrativa sáfica en México.
\end{abstract}

Palabras clave: Lesbianismo, literatura, sáfico, homosexualidad, género.

\section{Letters Lenchas: Towards a Historical Tour of Lesbian Literature in Mexico}

Abstract: The homoerotic discourse in Mexico, has been built in the last century, through artistic and media events; in this formulation, literature from the eighties, has played a decisive role to give a voice to those who thanks to the official discourse have been silenced. In the nineteenth century, early and mid-twentieth century, lesboliterature found a place suffocated by social prejudice, double standards and imminent repulsion of the population, which considered the nonheterosexual as sick or deviant. It was not until the eighties, with the appearance of Amora (1989) of Rosamaría Roffiel, that the Sapphic lyrics found a place to develop. The following article introduces some of the most important books ever written in Sapphic narrative in Mexico.

Key words: Lesbianism, literature, Sapphic, homosexuality, gender.

El discurso heteropatriarcal ha definido el ser y el deber ser de las homosexuales. Ser lesbiana ha sido sinónimo de rechazo, marginación, burla; calificativos como lencha, machorra o manflora ${ }^{4}$, presentes en el discurso cotidiano, son ejemplo fehaciente de homofobia.

\footnotetext{
${ }^{1}$ Fecha de recepción: 30/09/2014.

Fecha de aceptación: 20/10/2014.

${ }^{2}$ Doctora en Literatura Hispánica con especialidad en estudios de género y Coordinadora del Doctorado en Literatura Hispanoamericana, Benemérita Universidad Autónoma de Puebla, Puebla, México; $\square$ avrami0@yahoo.com.

${ }^{3}$ Profesor de Literatura Mexicana. Benemérita Universidad Autónoma de Puebla, Preparatoria Universidad Iberoamericana Puebla, Puebla, México; $₫$ gallegosv.jorgeluis@gmail.com.

${ }^{4}$ Lencha, manflora o machorra son sinónimos de lesbiana.
} 
El discurso homosexual en México ha estado marcado por la clandestinidad: ha ido de lo marginal al pecado, de lo oculto a lo visible, configurándose desde la ausencia y el silencio. Hortensia Moreno Esparza explica que éste es "el conjunto de simbolismos y maneras de significar que organizan la experiencia de las personas interpeladas por esa identidad, en oposición, [...] con las identidades no homosexuales" (Moreno 2010: 3-4); es decir, se forja con la instauración de significantes que se adhieren y quebrantan la ideología heterocentrica-patriarcal.

Los primeros textos lésbicos, surgieron, incluso, antes de los movimientos feministas y lésbico-gay iniciados hacia la segunda mitad del siglo XX. Éstos, fueron escritos, la mayor parte de ellos, por hombres heterosexuales, quienes vieron en las letras una posibilidad de plasmar sus fantasías eróticas y vistas desde una perspectiva masculina.

Se tienen vestigios que desde la antigüedad clásica, alrededor del 600 a.C., tuvieron origen los primeros textos lésbicos. Se atribuyen a Safo las primeras composiciones amorosas entre mujeres, convirtiéndola en uno de los pilares fundamentales de las creaciones homoeróticas. El verso "Me he enamorado de ti hace, Atis, ya tiempo.../ me pareciste una niña bajita y sin gracia..." (Cruz 2010: 59) es muestra de que el amor descrito en sus textos era aquel que profesaba entre sus discípulas a quienes enseñaba el arte de la poesía.

La vida en el monasterio fue el medio idóneo para que las mujeres expresaran su amor hacia otras mujeres. El género epistolar sirvió para que, en el siglo XII, una monja del monasterio de Tegersee, en Braveria, expresara el dolor que sentía al estar separada de su amada; Francis Mark Mondimore reproduce dichos versos:

¿Qué fuerza me permitirá soportarlo, / ser paciente en tu ausencia?/ ¿Tendré la fuerza de la roca, / y podré esperar tu regreso?/ Peno incesantemente noche y día como quien ha perdido una mano o un pie./ Todo lo agradable y delicioso/ parece sin ti lodo bajo los pies./ Derramo lágrimas cuando solía sonreír,/ y mi corazón no se alegra nunca./ Cuando recuerdo los besos que me dabas,/ y cómo acariciabas mis senos con tiernas palabras,/ deseo morirme por no poder verte./ ¿Qué más puedo 
decir?/ ¡Vuelve a casa, dulce amor!/ No prolongues más tu viaje;/ ya no puedo soportar tu ausencia./ Ve con Dios./ Recuérdame. (cit. pos. Lizarraga 1998: 76)

En México, Sor Juana Inés de la $\mathrm{Cruz}^{5}$ es considerada como la precursora de los primeros versos lésbicos latinoamericanos. Mucho se ha dicho que la décima musa siempre quiso ser hombre y que, incluso, llegó a travestirse bajo el seudónimo de Felipe Sáenz Gutiérrez para poder participar en certámenes de creación literaria y que vio en la vida del monasterio una forma de tener acceso a las letras. Se tienen contabilizados un total de treinta y ocho poemas, escritos entre 1680 y 1683, dedicados a María Luisa Manrique de Lara Gonzaga y Luján, condesa de Paredes de Nava, quien fuera su principal benefactora, en donde se puede apreciar una posible relación lesboerótica entre ambas: ${ }^{6}$ "Ser mujer, ni estar ausente,/ no es de amarte impedimento;/ pues sabes tú, que las almas/ distancia ignoran y sexo" (de la Cruz 2009: 27), o bien: "Tú eres Reina, y yo tu hechura; tú deidad, yo quien te adora;/ tú eres dueño, y yo tu esclava;/ tú eres mi luz, yo tu sombra./ Mientras yo le pido a Dios,/ que te acuerdes, gran Señora,/ que nací para ser tuya,/ y aunque tu no lo conozcas" (de la Cruz 2009: 60). Con estos versos, Sor Juana evidencia no sólo su capacidad creadora como poeta, sino también el vínculo afectivo establecido con la virreina, instituyendo así las primeras líneas, en las letras mexicanas, de una mujer que demuestra su admiración a otra mujer.

\section{La lesboliteratura según María Elena Olivera Córdova:}

ha adquirido relativa solidez sólo recientemente y un importante auge a partir de los últimos años del siglo XX y los primeros del XXI, el cual ha respondido a la creciente necesidad de organización y visibilización de las mujeres homosexuales, quienes difuminadas frecuentemente en los grupos feministas o en las organizaciones

\footnotetext{
${ }^{5}$ En el libro Intento de psicoanálisis de Juana Inés y otros ensayos Sorjuanistas (1988), Fredo Arias de la Canal expone, a través del uso de la teoría de Freud, la presunta homosexualidad de la décima musa. A través de ese estudio, el autor se cuestiona sobre las declaraciones de un amor ambiguo insertos en sus versos.

${ }^{6}$ No es gratuito que el género que se les atribuya a las lesbianas sea el de la poesía, ya que éste es un género que le permite, al que escribe, expresar sentimientos de manera más íntima, además de ser marginal; mientras que la narrativa es menos libre por pertenecer a un mercado industrializado.
} 
homosexuales, con los que han compartido la lucha por la obtención de derechos, no habían hablado de su propia especificidad. (Olivera 2009: 14)

La lesboliteratura encontró, en el siglo XIX, principios y mediados del XX, un espacio silenciado por prejuicios sociales, doble moral y rechazo inminente de la población que consideraba al no heterosexual como enfermo, rarito o desviado. En el XIX, por ejemplo, Dolores Guerrero, antologada por José María Vigil en Poetisas mexicanas (1893), escribe el poema $A$..., también referenciado como Nomás a tí (1852); en él, las normas heterosexuales se transgreden y expresa el deseo femenino:
A tí, joven de negra cabellera;
De tez morena y espaciosa frente;
De grandes ojos y mirada ardiente;
De labios encendidos de rubí;
De nobles formas y cabeza altiva;
De graciosa sonrisa y dulce acento;
De blancos dientes, perfumado aliento,
A tí te amo no más a ti. (Guerrero 1893: 81)

Resulta interesante que una escritora decimonónica dedicara versos a la imagen andrógina de un hombre, significando una trasgresión a los paradigmas heterofalocéntricos de la época, incorporando el erotismo sáfico, de manera velada, en la poesía nacional. ${ }^{7}$

Heraclio Castillo Velázquez, en "De la literatura como expresión del lesbianismo", cita a Rey David Rubalcaba quien hace una distinción entre literatura de mujeres y la lésbica, concluyendo que:

\footnotetext{
${ }^{7}$ Olivera Córdova explica que este poema sugiere "la feminización del objeto masculino de deseo, como ocurre en otros poemas de Dolores Guerrero: aunque -agrega la autora- es inútil entrar en especulaciones en torno a la razón de este recurso que no llevarían a ninguna conclusión sustentada" (Olivera 1999: 42).
} 
para reconocer a una literatura de corte lésbico, basta con cuantificar qué cantidad de mujeres tienen sexo, o más aún, si los personajes principales tienen relaciones sexuales entre ellas o no. Eventualmente, no es tan fácil reconocer [...] el contenido lésbico, ya que entre mujeres siempre hay más contacto físico y cariñoso, por lo que no sólo es complicado identificar un texto lésbico si no más complicado aún es saber quién lleva una vida lésbica en el mundo real, aunque no se pueden dejar pasar tan fácilmente las pistas obvias y claras de alguien que es de «ambiente». (cit. pos. Castillo 2008: 3-4)

Bajo esta perspectiva, la literatura sáfica se inscribe en las isotopías del amor, sexualidad y erotismo, buscando que la escritura pueda reflejarse en el espejo de un "уо" legitimado a través de un "yo" lésbico.

A principios del siglo pasado se reprodujeron los erróneos imaginarios históricos y estereotipos negativos que, hasta la fecha, han arrastrado a las lesbianas. Angie Simonis, en el artículo Retratos en sepia: las imágenes literarias de las lesbianas a principios del siglo $X X$, plantea cuáles son las dos posibilidades de las imágenes falsas presentadas en las letras:

- El de la lesbiana masculina, imitadora del comportamiento y la apariencia de los hombres, que presenta como su opuesta/ compañera a la lesbiana femenina, extremo de la delicadeza, pasividad y dedicación a su pareja/opuesta, reproduciendo la dicotomía heterosexual de los roles de género (la pareja butch/feme en el lenguaje de la teoría feminista lesbiana).

- El de la lesbiana como objeto altamente sexualizado o producto de la pornografía, que practica el sexo con otras mujeres como ser asexuado o, como variante de ésta, la insatisfecha sexualmente que no ha tenido la oportunidad de disfrutar los «verdaderos» placeres con un hombre. (Simonis 2009: 14)

Las primeras personajas ${ }^{8}$ lésbicas aparecen, en la literatura mexicana, a principios del siglo pasado. Fue en 1903 cuando Federico Gamboa en Santa, novela que gira en

\footnotetext{
${ }^{8}$ El término personaja, utilizado por Consuelo Meza Márquez en Utopía feminista. Quehacer de cuatro narradoras mexicanas contemporáneas (2000), y retomado por María Elena Olivera Córdova, para
} 
torno a una prostituta, presenta a una mujer homosexual: la Gaditana. Ésta es compañera de oficio y enamorada de Santa. Con ella Gamboa, en el capítulo v de la primera parte de su obra más representativa, muestra una galería de personajes sórdidos, dándole voz a una mujer que es capaz de mostrar su amor a otra mujer: “- ¡Hipo!, ya no aguanto a la Gaditana. Figúrese usted que está empeñada en que yo la quiera más que a cualquier hombre, ¿se habrá vuelto loca...?” (Gamboa 2002: 66).

A pesar de ello, el mismo autor muestra el rechazo que existía hacia la homosexualidad femenina considerándola como un acto perverso, indecente, una anormalidad, un acto propio de las prostitutas, como:

el vicio más ancestral y teratológico que de preferencia crece en el prostíbulo, cual en sementera propicia en la que sólo flores tales saben germinar y aun adquirir exuberante lozanía enfermiza de loto del Nilo; era el vicio contra la naturaleza; el vicio anatemizado e incurable, precisamente porque es vicio, el que ardía en las venas de la Gaditana impeliéndola con voluptuosa fuerza a Santa, [...] que quizá no lo practicaría nunca, contentándose, si acaso, con probarlo, escupir y enjuagarse, según escupimos y nos enjuagamos cuando por curiosidad inexplicable y poderosa probamos un manjar que nos repugna. (Gamboa 2002: 66)

Casi cien años después de la aparición de Santa de Gamboa, Cristina Rivera Garza publica Nadie me verá llorar (1999) ubicada en la década de los veinte; en el capítulo V titulado La Diablesa, Rivera Garza convierte a sus personajas Matilda Burgos «la Diablesa» y Ligia «la Diamantina» en Santa y en la Gaditana. En primera instancia, hace una referencia sobre la obra de Federico Gamboa, ${ }^{9}$ para explicar el porqué del acercamiento sexual entre los dos:

referirse a los personajes femeninos creados por la pluma de una mujer. Este término hace énfasis en la transgresión lingüística, elemento significativo en la narrativa sáfica. Elena Madrigal apunta que: "[1]a crítica literaria del corpus de tema lésbico en México debe la adopción del término "personajas" a María Elena Olivera [...], quien a su vez lo retomó de [...] Amora, de Rosamaría Roffiel [...]. El hacer explícito el género de los sujetos ficcionalizados es parte de la rebeldía socio-lingüístico-sexual que permea la novela [...]" (Madrigal 2011: 93).

${ }^{9}$ Cristina Rivera Garza anota sobre la obra de Gamboa lo siguiente: "En 1903, el escritor y diplomático mexicano Federico Gamboa publicó Santa, su novela más vendida. Basada en experiencias de su vida y utilizando los recursos del naturalismo literario, Gamboa describió con detalle la caída en la concupiscencia 
En la madrugada sola, sin clientes ya, las dos durmieron en la misma cama, las piernas enredadas como trenzas.

«La Gaditana» no tuvo la misma suerte. En la novela de Federico Gamboa, Santa solo fue capaz de comprender las insinuaciones nada sutiles de la Gaditana a través de las explicaciones que le dio, entre todos los hombres, un pianista ciego. Así, gracias a la atinada intervención masculina, Santa llegó a descifrar el contenido erótico de los vientres juntos durante las lecciones de baile y los besos que «la Gaditana» dejaba en su ropa todavía tibia. Entonces, naturalmente, Santa reaccionó con asco. Cuando «la Diablesa» y «la Diamantina» leyeron el pasaje juntas, no sólo pudieron evitar las carcajadas sino que además hicieron el amor sobre las páginas del libro. ¡Ay, pobre embajador Gamboa, tan cosmopolita y tan falto de imaginación! (Rivera 1999: 173-174)

Rivera Garza no sólo refleja las pasiones lésbicas en una época en la que ni siquiera se tenía una noción de qué era ser lesbiana, sino que también resignifica la relación homoerótica de Santa y la Gaditana, la hace posible, las reivindica, haciendo una crítica a la sociedad de principios de siglo: una sociedad que consideraba al otro como un auténtico desconocido, como un anormal, como un enfermo o un desviado.

La segunda mitad del siglo XX, en México, fue vertiginosa. E1 2 de octubre de 1978 un contingente del Movimiento de Liberación Homosexual, en el que participó Nancy Cárdenas, ${ }^{10}$ desfiló para protestar y remembrar las atrocidades acaecidas años atrás. A partir de ese momento, surgieron grupos que dignificaron, y siguen dignificando, la figura y la presencia de los y las homosexuales. ${ }^{11}$

de la muchacha de Chismalistac cuyo nombre por sí solo, a decir de doña Elvira, la dueña de la casa de citas, le aseguraría ganancias enromes. La novela ganó fama de atrevida, y los hombres letrados de la clase media pagaron con gusto por la historia para verse reflejados en sus páginas y lavar su corazón con un perdón tardío" (Rivera 1999: 160).

${ }^{10}$ Locutora, poeta, dramaturga, documentalista y activista que luchó por los derechos lésbico-gay; tres años antes de la primera marcha escribió, junto con Monsiváis, el "Manifiesto en defensa de los homosexuales en México" (1975); en 1974, fue artífice del Frente de Liberación Homosexual (FLH), siendo la primera asociación de su tipo en México; en 1973, declaró su homosexualidad en el noticiero 24 horas, mientras era entrevistada por el despido de un empleado de Sears por ser homosexual.

${ }^{11}$ El motivo de las marchas fue $-\mathrm{y}$ ha sido- terminar con la discriminación, hostigamientos sexuales, despidos injustificados, negación de servicios públicos de salud, erradicar el linchamiento mediático, así 
La izquierda mexicana tomó una actitud de tolerancia e inserción de grupos minoritarios -incluidos no sólo homosexuales, sino también mujeres, prostitutas, personas con capacidades diferentes, indígenas-, pugnando contra el sexismo, la homofobia, crímenes de odio, feminicidios, etc. ${ }^{12}$ La apertura a los lesboerotismos dio como resultado que, en la década de los ochenta, el discurso de la diferencia se evidenciara en la sociedad, la cultura popular y las artes; las imágenes falsas comenzaron a desdibujarse para dar paso a una representación verosímil de lo, hasta entonces, considerado como abyecto, sucio, pecaminoso, desconocido.

Xabier Lizárraga analiza la conformación del discurso homosexual de los ochenta y principios de los noventa; para él, "fue posible observar un fenómeno: las homosexualidades [...] buscan el perdón, la tolerancia, la supervivencia clandestina, mientras que las gaycidades persiguen una calidad de vida, antes que una cantidad" (Lizárraga 2003: 175). Los grupos homosexuales vieron en el SIDA, llamado también cáncer rosa o cáncer gay, a su peor enemigo; fue entonces cuando se reconocieron las transformaciones que homosexuales hicieron en la cultura nacional; las historias de vida pasaron de ser acalladas a narraciones que ofendieron las buenas costumbres que transgredieron normas, paradigmas sociales, desafiaron y encararon el cáncer rosa, el amor de pareja, miedos y prejuicios introyectados por la sociedad, aceptando un discurso plural: de y desde la diferencia.

En 1941, José Revueltas en Los muros del agua, presenta a Soledad, personaja que desde el espacio carcelario está condenada a amar a Rosario desde lejos. Asimismo, Guadalupe "Pita" Amor, en Galería de titeres, exhibe a Raquel Rivadeneira, una viuda que es seducida por otra mujer; Olivera analiza a la personaja homosexual, concluyendo que ésta se encuentra "apenas bosquejada y aparece menos definida aún que La Gaditana (de Santa) y Soledad (de los Muros de agua), entre otras cosas, dicha personaja ni siquiera tiene un nombre" (Olivera 2009: 93); no obstante "su participación en la historia es

como la pugna contra el SIDA; estas movilizaciones impulsaron la salida masiva del clóset, planteando que el verdadero dolor se centra en la homofobia.

${ }^{12}$ Esta apertura dio como resultado que en el 2010 entrara en vigor, en la Ciudad de México, la Ley que aprobó el matrimonio entre personas del mismo sexo y la legalización de la adopción de infantes por matrimonios de parejas homosexuales, siendo la primera en América Latina. 
fundamental para combatir su soledad, $[. .$.$] la narradora la percibe como una humana que$ sufre, no por un rechazo tajante sino por el vaivén sentimental de Raquel, al que se somete" (Olivera 2009: 93).

Las letras lésbicas vieron en la poesía un escaparate para experimentar y evidenciar el erotismo de personas que aman a personas del mismo sexo. Nancy Cárdenas, Reyna Barrera, Rosario Castellanos, Sabina Berman y Silvia Tomasa Rivera esbozaron relaciones eróticas entre mujeres; Castellanos, en Kinsey report (1972), dibujó seis mujeres distintas; una de ellas evidencia, a través de sus estrofas, una relación lésbica.esbozaron estrofas que van de lo andrógino a lo homoerótico:

\footnotetext{
A los indispensables (como ellos se creen)

los puede usted echar a la basura, como hicimos nosotras.
}

Mi amiga y yo nos entendemos bien.

Y la que manda es tierna, como compensación;

así como también, la que obedece,

es coqueta y se toma sus revanchas.

Vamos a muchas fiestas, viajamos a menudo

y en el hotel pedimos

un solo cuarto y una sola cama.

Se burlan de nosotras pero también nosotras

nos burlamos de ellos y quedamos a mano

Cuando nos aburramos de estar solas

alguna de las dos irá a agenciarse un hijo.

¡No, no de esa manera! En el laboratorio

de la inseminación artificial. (Castellanos 1975: 319-20) 
El lesbianismo tenía una connotación negativa, en la literatura, hasta que en 1964 aparece la primera historia cuyo eje central es una personaja homosexual: Figura de paja de Juan García Ponce. El argumento de la historia se centra en la construcción de identidades a partir de un triángulo amoroso entre Teresa, Leonor y el personaje masculino: el suicidio de Leonor sirve para desenmascarar la frustración amorosa. A estas personajas se añaden los de Lucero y Pepa de Las dulces de Beatriz Espejo, siendo las dos últimas las primeras personajas homosexuales representadas por la pluma de una mujer.

Las letras mexicanas de los años ochenta y principios de los noventa viraron la mirada hacia temas políticos, urbanos y denuncia; ciudad, clase media, juventud, rock, violencia, poder, mujeres, homosexuales, migración, lesbianas, mass media, ironía, Historia, drogas, moda y religión fueron los temas en torno a los cuales giraron las propuestas literarias; las temáticas se presentaron en forma de notas periodísticas, grabaciones, diarios, autobiografías, crónicas o cuentos; es ahí donde los disidentes sexuales encontraron un escaparate para ejercer resistencia contra la heterosexualidad obligatoria.

Esta década significó, también, un puente entre la narrativa de los setenta y los noventa; además, convivieron autores como Octavio Paz, Juan Rulfo, Jorge Ibargüengoitia, Elena Garro, Rosario Castellanos, Elena Poniatowska, Carlos Fuentes y José Emilio Pacheco, con una nueva generación que refrescó la propuesta literaria: Laura Esquivel, Ángeles Mastretta, Óscar de la Borbolla, Eusebio Ruvalcaba. Juan Villoro, Sergio Pitol, Rafael Pérez Gay, José Joaquín Blanco, Enrique Serna, María Luisa Puga, Héctor Aguilar Camín, Rosamaría Roffiel y Luis Zapata, por nombrar algunos.

Miguel G. Rodríguez Lozano, en “Instantáneas de una década: narrativa mexicana, 1980-1990" cuenta que:

se cierra la etapa gris pos 68 , con la guerrilla urbana y rural; se perciben ya los desfases del estado priísta y la actuación de una sociedad masiva dispuesta a cambiar [...]. Entre 1980 y 1990, se preparó el terreno para el arribo de la última década y la entrada del siglo XXI. [...] lo sucedido es de importancia para sopesar los procesos 
por los que ha pasado la literatura de nuestro país y en concreto la narrativa (Rodríguez 2012: 96-7).

Fue a finales de los sesenta cuando la literatura de tema homosexual tomó importancia; hasta antes de esa década, según lo explica Mario Muñoz en De amores marginales. 16 cuentos mexicanos, la literatura mexicana:

soslayó su existencia al dejarse llevar por el pudor, y también este silencio debe atribuirse a las reticencias morales [...]. [L]as escasas aportaciones que había sobre el tema parecían indicar que éste no formaba parte del amplio registro de realidades de que se han nutrido nuestros escritores. (Muñoz: 1996: 14)

Son cinco los textos fundacionales del tema lesbo y homoerótico: El diario de José Toledo (1964) de Miguel Barbachano Ponce, Después de todo (1969) de José Ceballos Maldonado, El vampiro de la colonia Roma de Luis Zapata, Amora de Rosamaría Roffiel y Dos mujeres (1990) de Sara Levi Calderón, todos ellos tienen como común denominador mostrar personajes que, hasta entonces, habían sido olvidados por la cultura heterofalocéntrica e insertándose en terrenos de la posmodernidad.

Según Raymond L. Williams y Blanca Rodríguez, en La narrativa posmoderna en México, las letras post se caracterizan por "la discontinuidad, la ruptura, el desplazamiento, el descentramiento, lo indeterminado y la antitotalidad. [...] suele subvertir los discursos dominantes" (Raymond 2002: 20). Bajo esta perspectiva, se incrusta la literatura lesbo y homoerótica; ésta origina significaciones a partir de las representaciones que rompen y transgreden paradigmas del heterocentrismo, reconstruyendo y resignificando lo forjado en el entramado simbólico-cultural desde la mirada de una heterosexualidad que ha silenciado todo lo distinto a ella; desarticula el sistema binario masculino/femenino en la que el deseo sexual se opone a lo biológico, entendiendo esto último como lo normativo, lo dado, lo predeterminado por la genitalidad. 
Es precisamente en esta década, cuando se dio un auge de las creaciones homoeróticas; estas aportaciones dieron a la literatura mexicana una apertura a temas donde se lleva a la sublimación el amor gay, ya fuera desde una homosexualidad asumida o bien desde el clóset, y los movimientos lésbico-gay como parte de una contracultura que impregna los ámbitos culturales y sociales. Amora (1989), de la escritora veracruzana Rosamaría Roffiel, está considerada como la primera novela mexicana en abordar el amor entre dos Evas de forma explícita.

Narrada en primera persona, Amora es un libro que nos cuenta la vida de Guadalupe, una activista feminista, quien gracias a su participación en estos grupos ayuda a mujeres que han sido violadas; también es articulista en la revista Feme, es lesbiana y tiene una relación con una mujer llamada Claudia, quien en apariencia es buga. ${ }^{13}$ Las constantes indecisiones de Claudia y el problema moral que le causan tener una relación homosexual, generan en Amora -como es nombrada Guadalupe por Claudia-, desesperación; sin embargo, ella resiste gracias al amor.

La primera, y hasta ahora única novela de Roffiel, ha sido marginada de la Historia literaria, aunque, según Antonio Marquet, en el artículo "La pasión según Roffiel” (2001), Amora ocupó el tercer lugar de ventas en 1989, sólo después de El general en su laberinto y Como agua para chocolate.

A pesar que su obra literaria no es amplia, Rosamaría Roffiel, ha hecho que se le califique como una escritora que ha transgredido las normas del heterocentrismo literario, dejando un legado no sólo en las letras lésbicas, sino también en las nacionales. Sus creaciones se insertan dentro de la tradición literaria femenina de los ochenta, aquella que se atrevió a cuestionar los roles patriarcales que le han sido conferidos a la mujer. Morna Dick, cita a Nuala Finnegan, quien considera que el trabajo de Roffiel "concentrating on the ways in which they continue the Castellanos trajectory, re-writing aspects of Castellano's work and forging paths for self-exploration of the Mexican female subject in the late twentieth century" (cit. pos. Dick 2011: 35). En "Una charla con Elena

\footnotetext{
13 Vocablo que pertenece al argot de los grupos homosexuales que sirve para definir a las personas heterosexuales.
} 
Poniatowska", realizada por Iliana Alcántar, Marisol Castillo, Marisol Pérez y Melissa Strong Carrillo (2013), la autora destaca la importancia de esta novela y de Rosamaría, al afirmar que "es una gran escritora. [...] ha sido [complicado] para ella reventar toda esta capa de ostracismo, de rechazo. Por ejemplo, a sus libros, un libro que se llama Amora, en vez de amor, lo sacaban de las librerías, no lo distribuían, no lo circulaban, todo eso fue muy difícil" (Alcántar 2013: 78).

Dos mujeres (1990) de Sara Levi Calderón es un relato autobiográfico, donde la narradora, en primera persona, cuenta la vida de Valeria, una mujer que pertenece a una familia poderosa de la comunidad israelita de México; su padres, procedentes de Lituania, arribaron a México huyendo de Hitler y pronto comenzaron a tener éxito económico. La problemática gira en torno a las relaciones de familia, la autoridad del padre y la sumisión femenina.

Infinita (1992) de Ethel Krauze narra la historia de un amor frustrado entre Delfina -Fina, Finita, Infinita- y Leonor, dos amigas que establecen una relación sin tomar en cuenta su orientación sexual, configurando un triángulo amoroso entre ambas y el cónyuge de Delfina. En La muerte alquila un cuarto (1991) de Gabriela Rábago Palafox, escritora de relatos de ciencia ficción, aborda cómo son las parejas homosexuales, femeninas y masculinas, de clase media; presenta a Gabriela, un personaje obsesivo que se encuentra inmersa en dos sectores ampliamente marginados: el homosexual y el de los enfermos de sida.

Por otra parte, Réquiem por una muñeca rota (cuento para asustar al lobo) (2000) de la sonorense Eve Gil cuenta la transición de la adolescencia a la madurez de dos mujeres: Vanessa y Moramay, cuyo principal problema será la disyuntiva entre acatar los roles familiares de sumisión o transgredir las normas sociales. Moramay encuentra en la literatura un medio de subversión, mientras que Vanessa recurre a la explotación, de manera consciente, de su sexualidad.

Con fugitivo paso de Victoria Enríquez (1997) es un libro de cuentos que recurre al pasado novohispano para desenmascarar el amor lésbico. Sandra, secreto de amor (2001) de Reyna Barrera se enmarca dentro del Festival Cervantino y cuenta los conflictos 
amorosos entre Sandra y Ramona, abordando el travestismo y el sida. Mientras que Gilda Salinas en Las sombras del Safari (1998) cuenta el amor lésbico a través del espacio, siendo el club nocturno del Distrito Federal el lugar para enmarcar el amor prohibido por la sociedad machista.

De Ana Klein destacan Si me regreso me muero (1984), La princesa en los espirales de la luna (2008) y No hay princesa sin dragón (2004); éste último resulta ser una narración autobiográfica. Es la mayor aportación de Klein contarnos la historia de Camila Caminos y su amor por María, en medio del movimiento juvenil del 68 y el ataque de los halcones de 1971. Es así como la historia toma tintes políticos y establece una crítica hacia el sistema político mexicano y la represión no sólo hacia los jóvenes sino también hacia las lesbianas.

En Casa de la Magnolia (2004), el escritor poblano Pedro Ángel Palou nos entrega la historia de Maia, joven que se enamora de Adriana, quien tiene como único motivo encontrar el olvido en la muerte, convirtiendo al amor en una vía de perdición. ¿Y qué fue de Bonita Malacón? (2007) de José Dimayuga nos presenta la mujer más hermosa de Palma de Gorda, Guerrero, narrando cómo Bonita se convierte en reina de belleza y actriz de cine e irremediable caída en las drogas. En Tren nocturno (2007) María Luisa Medina hace una reflexión no sólo sobre el amor lésbico, sino también del ser.

En el Manual de la buena lesbiana (2009) y Manual de la buena lesbiana 2 (2013), Ana Francis Mor nos regala una guía cómica sobre las complejidades del mundo lésbico, ofreciéndonos, desde la cotidianeidad, temas de reflexión sobre la vida de las mujeres que aman a otras mujeres. Por su parte, Contarte en lésbico (2010) de Elena Madrigal, un libro que hace una compilación de cuentos lesboeróticos, presenta un abanico de mujeres que, desde el mundo de lo cotidiano, toman decisiones sobre su cuerpo erotizado.

El beso de la virreina (2010) de José Luis Gómez es una novela histórica que gira en torno a la figura de Sor Juana Inés de la Cruz; en la historia, el autor da un guiño hacia la sexualidad de Juana de Asbaje quien desde niña fue hostigada sexualmente por su padrastro; no obstante, el beso dado a la virreina Rosa de Mendoza se configura como un encuentro espiritual. 
María Luisa Medina en Miel azul (2012) da cuenta del amor entre dos mujeres inmersa en una historia romántica en la que ambas tienen que sortear una serie de vicisitudes para poder estar juntas; Crema de vainilla (2014) de Artemisa Téllez es una novela corta que presenta una relación, basada en el masoquismo, entre una profesora universitaria y una alumna.

A partir del nuevo milenio, los temas lésbicos en la literatura han tenido un florecimiento debido a la reivindicación de los derechos sexuales, la lucha por la no discriminación, así como la incorporación de los estudios de las creaciones queer en el ámbito académico; Violeta Barrientos, en Construyendo una tradición poética lesbiana de otras «rarezas» en Sudamérica añade que esta reivindicación se debe, también, a que "[e]stos discursos nos hablan de una escritura que se va afianzando de manera osada en la tradición erótica literaria en general (...)” (Barrientos 2009: 178).

Olivera Córdoba explica que todas las obras tienen como común denominador "ficcionalizar la experiencia lésbica, [...] legitimar las relaciones amorosas, eróticas y/o sexuales entre mujeres, como subversión ante la sociedad patriarcal y los cánones literarios tradicionales, al disentir de su heteronormatividad tácita, y proponer formas distintas de ficcionalización" (Olivera 2009: 29).

Gracias a la presencia de autoras y autores que abordan con mayor frecuencia lo lesboerótico, se puede afirmar que existe una literatura sáfica que surge a partir de la necesidad de reconocimiento y de autoexploración en temas que han sido vedados por el patriarcado; asimismo, esta literatura toma conciencia de la sexualidad periférica, las expone y rompe con los esquemas binarios propuestos por la cultura heterocentrista; también, se están sentando las bases para la construcción de una tradición de escritura lesboerótica, en la que la representación y el resquebrajamiento de los estereotipos es la principal apuesta. El mayor logro de las escritoras sáficas ha sido la transgresión de las reglas que la heteronormatividad ha impuesto a la expresión de las disidencias lesboeróticas, recomponiendo la sexualidad femenina, el cuerpo y el erotismo, así como la cotidianeidad de las mujeres que se atreven a contar su historia por encima de los preceptos falocéntricos; además, rompen con los esquemas del imaginario femenino, los 
estereotipos tradicionales sobre lo que debe ser una mujer mostrando que el género es un constructo social.

\section{Referencias Bibliográficas}

Alcántar, Iliana; Marisol Castillo; Marisol Pérez y Melissa Strong Carrillo. 2003. "Una charla con Elena Poniatowska." Mester, 32: 72-84.

Amor, Guadalupe. 1959. Galería de títeres. México: FCE.

Arias de la Canal, Fredo. 1988. Intento de psicoanálisis de Juana Inés y otros ensayos Sor Juanistas. México: Frente de Afirmación Hispanista.

Barrera, Reyna. 2001. Sandra secreto de amor. México: Plaza y Valdés.

Barrientos, Violeta. 2009. "Construyendo una tradición poética lesbiana de otras «rarezas» en Sudamérica". Ellas y nosotras: Estudios lesbianos sobre literatura escrita en castellano. Coord. Elina Norandi. Madrid: Eagles. 167-98.

Castellanos, Rosario. 1975. “Kensey report.” Poesía no eres tú, obra poética 1948-1971. México: FCE. 319-320.

Castillo Velázquez, Heraclio. 2008. "De la literatura como expresión del lesbianismo" Revista de Investigación Científica, 4, 2, mayo - agosto 2008: 1-8.

Cruz, Sor Juana Inés de la. 2010. Obras completas. México: Jorge Porrúa.

Dick, Morna. 2011. Amamos Diferente: Creating the Imagined Lesbian Community in Rosamaría Roffiel's Amora, Sara Levi Calderón's Dos Mujeres and Reyna Barrera's Sandra secreto de amor. Glasgow: University of Glasgow. Tesis no publicada.

Dimayuga, José. 2007. ¿Y qué fue de Bonita Malacón? México: Jus. 
Enríquez, Victoria. 1997. Con fugitivo paso. México: V. Enríquez.

Espejo, Beatriz. 1979. “Las dulces”. Muros de azogue. México: Diógenes. 55-60.

Gamboa, Federico. 2002. Santa. México: Época.

García Ponce, Juan. 1968. Figura de paja. México: Joaquín Mortiz.

Gómez, José Luis. 2008. El beso de la virreina. México: Planeta Mexicana.

Gil, Eve. 2000. Réquiem para una muñeca rota (cuento para asustar al lobo). México: CONACULTA.

Krauze, Ethel. 1992. Infinita. México: Joaquín Mortiz.

Klein, Ana. 1984. Si me regreso me muero. México: Jorge Porrúa. .2004. No hay princesa sin dragón. México: Hoja Casa Editorial. 2008. La princesa en los espirales de la luna. México: AGT.

Levi Calderón, Sara. 1990. Dos mujeres. México: Diana.

Lizarraga Cruchaga, Xabier. 2003. Una historia sociocultural de la homosexualidad: Notas sobre un devenir silenciado. México: Paidós.

Madrigal, Elena. 2010. Contarte en lésbico. México: Ediciones Alondras. 2011. "Un carnaval para el yo lésbico: los cuentos de Gilda Salinas". Lectora, 17: 93-103.

Marquet, Antonio. 2001. "La pasión según Roffiel.” iQue se quede el infinito sin estrellas! La cultura gay al final del milenio. México: Universidad Autónoma Metropolitana. 229-232.

Medina, María Luisa. 2007. Tren nocturno. México: Ediciones B. 2010. Miel azul. México: LesVOZ. 
Meza Márquez, Consuelo. 2000. La utopía feminista: Quehacer literario de cuatro narradoras mexicanas contemporáneas. México: Universidad Autónoma de Aguascalientes.

Mor, Ana Francis. 2009. Manual de la buena lesbiana. México: Emeequis. .2013. Manual de la buena lesbiana 2. México: Emeequis.

Moreno Esparza, Hortensia. 2010 "La construcción cultural de la homosexualidad." $\begin{array}{lllllll}\text { Revista digital universitaria, } & 11, & 8 & \text { (2010): } & \text { 1-9. }\end{array}$ http://www.revista.unam.mx/vol.11/num8/art79/\#up [10 sept. 2014]

Muñoz, Mario, comp. 1996. De amores marginales. 16 cuentos mexicanos. México: Universidad Veracruzana. Impreso

Olivera Córdova, María Elena. 2009. Entre amoras: Lesbianismo en la narrativa mexicana. México: UNAM, Centro de Investigaciones Interdisciplinarias en Ciencias y Humanidades.

Palou, Pedro Ángel. 2004. Casa de la Magnolia. México: Random House Mondadori.

Rábago Palafox, Gabriela. 1991. La muerte alquila un cuarto. México: Planeta Mexicana.

Revueltas, José. 2013. Los muros de agua. México. Era.

Rivera Garza, Cristina. 1999. Nadie me verá llorar. México: Tusquets.

Rodríguez Lozano, Miguel. 2012. "Instantáneas de una década: narrativa mexicana, 1980-1990." Literatura hispanoamericana: juegos y estrategias. Tlaxcala: Universidad Autónoma de Tlaxcala. 77-98.

Rodríguez Tobal, Juan Manuel. 2010. "Nota preliminar”. Poemas y fragmentos. Safo. Trad. Juan Manuel Rodríguez Tobal. Madrid: Hiperión. 9-12.

Roffiel, Rosamaría. 2009. Amora. México: Raya en el agua.

Salinas, Gilda. 1998. Las sombras del Safari. México: Diana. 
Simonis, Angie. 2010. "Retratos en sepia: las imágenes literarias de las lesbianas a principios del siglo XX". Ellas y nosotras: Estudios lesbianos sobre literatura escrita en castellano. Coord. Elina Norandi. Madrid: Eagles. 12-80.

Téllez, Artemisa. 2014. Crema de vainilla. México. Voces en tinta.

Vigil, José María. 1893. “Dolores Guerrero.” Poetisas mexicanas. Antología formada por encargo de la junta de señoras. México: Oficina Tip. de la Secretaría de Fomento. 8184.

Williams, Raymond L. y Blanca Rodríguez. 2002. La narrativa posmoderna en México. México: UV. 